\title{
OFERTA COMERCIAL, PUBLICIDAD E IMÁGENES EN TORNO A LA ÉLITE. VALPARAÍSO, 1900-1940
}

\author{
Commercial supply, publicity and images around elite. \\ Valparaiso, 1900-1940.
}

\author{
María Regina Henríquez (*)
}

\section{RESUMEN}

Mediante el uso de avisos publicitarios aparecidos en diarios y revistas circulantes en la ciudad de Valparaíso durante el periodo 1900-1940, este artículo busca dar cuenta de las imágenes en torno a la élite chilena que fueron utilizadas por la publicidad para ofertar determinados artículos, a los que se les asociaba la condición de expresión de estatus social a partir de su consumo. La oferta publicitaria contribuyó en este proceso a partir de la recurrencia a imágenes y textos, que no sólo representaban al producto publicitado sino también un determinado modo de vida.

\section{Palabras clave:}

Valparaíso, historia y publicidad, oferta comercial, élite de Valparaíso.

\footnotetext{
(*) Instituto de Historia, Pontificia Universidad Católica de Valparaíso. Valparaíso, Chile. Correo electrónico: henriquez19@ gmail.com

${ }^{1}$ La investigación que dio paso a este artículo se efectúo en el marco del Postdoctorado realizado durante 2012, en el Instituto de Historia de la Pontificia Universidad Católica de Valparaíso, el cual fue apoyado por esta universidad. En la búsqueda de información se contó con la colaboración del estudiante de Historia Lucas Pavéz.

Artículo recibido el 15 de diciembre de 2012. Aceptado el 18 de abril de 2013.
} 


\begin{abstract}
Using advertisements found in newspapers and magazines circulating in the city of Valparaiso during the period 1900-1940, this article seeks to explain the images around the Chilean elite that were used for publicity to offer specific products, to which were associated expression social status from its consumption. The publicity offer contributed to this process through recurrence to images and texts which not only represented the advertised product but also of a determined way of life.
\end{abstract}

Keywords:

Valparaíso, history and publicity, commercial supply, Valparaíso elite.

\title{
INTRODUCCIÓN
}

Para Víctor Domingo Silva, Valparaíso se debe a la República ${ }^{2}$. Tal señalamiento lo realiza resaltando que como pocas ciudades de Chile, este puerto necesitó "del aura regeneradora de la libertad para crecer y agigantarse, llegando a ser lo que es...: la segunda ciudad de Chile y su metrópoli comercial" 3 . Fue tras la consolidación de la Independencia, con la liberación del comercio, que esta ciudad adquirió la condición de metrópoli comercial dejando de ser lo que fue en el periodo colonial, "un poblacho mal construido y secundario, un aldeón a donde recurrían los santiaguinos por pura necesidad" ${ }^{4}$; siendo con el paso del siglo XIX uno de los puertos del Pacífico con mayor movimiento comercial, cuyo auge estuvo entre fines del siglo XIX y las primeras décadas del XX.

Un papel importante en el desarrollo de la actividad comercial de Valparaíso estuvo en manos de los extranjeros que arribaron a la ciudad -principal e inicialmente ingleses y franceses- en quienes quedó un amplio sector de lo conocido como

\footnotetext{
${ }^{2}$ Silva, Víctor Domingo. Monografía Histórica de Valparaíso 1536-1910. Viña del Mar: Ediciones Altazor, 2004:28. La edición original de este texto fue realizada por la Litografía e Imprenta Moderna en 1910, por encargo de la Comisión de Fiestas del Bicentenario.

${ }^{3}$ Ibíd.

${ }^{4}$ Ibíd.
} 
"gran o alto comercio", así como parte del comercio menor o detallista. Estos contribuyeron además, en el proceso local de mirar a Europa como un referente de estilo de vida asociado al refinamiento, la elegancia y el buen gusto; hecho posible de percibir por los locales en algunas de sus prácticas de consumo y comportamiento ${ }^{6}$. Tal mirada es señalada por Estrada, quien plantea que la historia de Valparaíso "se hace mirando hacia afuera, casi de espaldas a lo autóctono, evidenciando una gran sensibilidad por lo foráneo..." puerto constituye una referencia concreta de tal mirada. Al igual que Santiago, donde ciertos sectores de la población adquirían productos importados, Valparaíso también estaba "contaminado por Europa" en lo que respecta al consumo ${ }^{8}$. Los productos importados eran ofertados en la publicidad aparecida en diarios y revistas de circulación en la ciudad de Valparaíso, a partir de avisos que contenían imágenes y textos donde se asocia a las mercancías elementos diferenciadores o de expresión de estatus; con ello se buscaba promover el consumo en habitantes de la ciudad, en específico, en la élite del puerto.

En este trabajo se considera que obtener información sobre la oferta comercial y la forma en que se promociona el consumo, no sólo constituyen aspectos de interés para una perspectiva económica, también lo son para el análisis histórico, social y cultural de un determinado periodo, espacio o sector social. La forma en que es presentado el producto en un aviso publicitario por ejemplo, tanto en lo que se refiere a las imágenes como al texto utilizado, puede entregar información sobre el público al que se busca interesar y sobre lo que éste procuraba alcanzar a partir del consumo, que no sólo estaría relacionado con satisfacer necesidades materiales sino también simbólicas, como podría entenderse la búsqueda por

\footnotetext{
${ }_{5}^{5}$ El gran o alto comercio era un pequeño grupo de grandes firmas importadoras y exportadoras, que en su gran mayoría estaban en manos de extranjeros, principalmente ingleses, alemanes y estadounidenses. Entre ellas se encontraban las inglesas Williamson, Balfour \& Cía. establecida en 1852, y Graham Rowe \& Co., en 1842; así como la alemana Vorwerk y Cía. que se establece en 1846. Ver: Couyoumdjian (2012). A su vez, Yábar ubica en el alto comercio a almacenes de abarrotes, almacenes por mayor, almacenes de mercancías surtidas, casas importadoras, entre otros; mientras que en el comercio por menor identifica diversas actividades comerciales tales como carpinterías, mueblerías, paqueterías, tiendas de mercaderías surtidas, entre algunas. Yábar, Juan. Valparaíso 1536-1910. Recopilación Histórica, Comercial y Social. Valparaíso: Imprenta Minerva, (1910: 388).

${ }^{6}$ Guerra, Alejandra. "La imagen de sí: ser y parecer. El surgimiento de nuevos hábitos de consumo. Valparaíso 1840-1860". Tesis para optar al grado de Magíster en Historia. Valparaíso: Universidad Católica de Valparaíso. Facultad de Filosofía y Educación. Instituto de Historia, 2002: 66.

${ }^{7}$ Estrada, Baldomero. "Poblamiento e inmigración en una ciudad puerto. Valparaíso 1820-1920", Serie Monografías Históricas $\mathrm{N}^{\circ} 12$. Valparaíso, sociedad y economía en el siglo XIX. Baldomero Estrada, Eduardo Cavieres, Karin Schmutzer y Luz María Méndez, Instituto de Historia, Universidad Católica, Valparaíso, (2000: 45).

${ }^{8}$ Guerra, ob. cit., 66.
} 
expresar estatus o diferenciarse a partir del acceso a determinados productos ofertados comercialmente.

Para el estudio base de este trabajo se optó por el periodo 1900-1940, considerando que durante las primeras décadas del siglo XX, la ciudad de Valparaíso mantenía un dinamismo comercial que favorecía el arribo de mercancías diversas provenientes del extranjero, muchas de ellas dirigidas a un público específico, la élite porteña. A su vez, interesó conocer la publicidad de este periodo, por cuanto una primera revisión de impresos permitió observar cambios tanto en lo relativo al tipo de aviso publicitado (de un formato más simple con predominio de texto a uno más complejo con textos e imágenes más elaborados) y al incremento del número de avisos y de páginas con contenido publicitario. Se recurrió en específico a los diarios El Mercurio de Valparaíso y La Unión, así como a las revistas Sucesos y Zig$Z a g$, en razón a que los dos primeros constituyen medios locales y en el caso de las revistas, Sucesos aparece inicialmente en Valparaíso, dando cuenta de publicidad local y de acontecimientos de la ciudad, y con respecto a $Z i g-Z a g$, se optó por esta fuente considerando que cubre parte del periodo abordado, cuando ya no aparece Sucesos (1932-1940) y que tiene circulación en la zona.

\section{PUBLICIDAD, OFERTA COMERCIAL Y CONSUMO EN VALPARAÍSO}

Durante varias décadas, principalmente entre la segunda mitad del siglo XIX e inicios del XX, coexistieron en Valparaíso el alto comercio junto con el comercio al por menor, lo que contribuyó a que se diera una amplia oferta de mercancías, muchas de ellas extranjeras, entre las que se contaban: vestuario femenino y masculino, licores, telas y artículos de tocador. Esta oferta ser vio favorecida por la demanda existente en la ciudad, fortalecida a su vez por la valoración de los productos importados, en especial aquellos provenientes de Inglaterra y Francia, hecho que se enmarcaba en un proyecto cultural que miraba a Europa como modelo referente del comportamiento y consumo que prevalecía en los círculos sociales más prominentes de la sociedad chilena?.

\footnotetext{
${ }^{9}$ Palma, Daniel. "De apetitos y de cańas. El consumo de alimentos y bebidas en Santiago a fines del siglo XIX", Revista Historia, Instituto de Historia Pontificia Universidad Católica de Chile, 37/ II, julio-diciembre, 2004. Versión on line. Disponible en: <http://www.scielo.cl/scielo.php?pid=S0717-71942004000200005\&script=sci_arttext>. [consultado: el 5 de abril de 2012].
} 
La búsqueda del refinamiento y su asociación con Europa, en específico, con el estilo de vida de las clases más encumbradas de ese continente, ocurría desde el siglo XIX en la oligarquía chilena y permaneció hasta parte del siglo XX ${ }^{10}$. Francia e Inglaterra eran los referentes valorados en la búsqueda por imitar el estilo de vida asociado al refinamiento, al lujo, la sofisticación y el estatus social. A su vez, las modas provenientes de estos países, y en general los estilos de vida propios de las sectores importantes de Europa, eran vistas por la oligarquía chilena como las expresiones más legítimas de la civilización moderna ${ }^{11}$. Tal imitación cumplía una doble función, por una parte igualaba a los miembros del sector oligárquico a su referente externo -la aristocracia europea- y por otra, los diferenciaba y distanciaba de las otras clases sociales del país.

A su vez, el consumo de ciertos bienes, de tipo más bien conspicuo, está en conexión directa con lo que se ha denominado el "buen tono", que para Barros y Vergara "apunta a una vasta gama de patrones de conducta cuyo denominador común es el de estar regidos por la moda, vale decir, por esa convención que define todo aquello que es tenido por elegante y refinado" ${ }^{12}$. Para estos autores, el buen tono actúa y consume básicamente de prestado, al importar no sólo mercancías sino también "decires y etiqueta", al estar abierto a las influencias de "la moderna cultura europea" y al acoger "sin reservas los dictámenes de la moda de París y Londres"13. El buen tono está directamente relacionado con un modo de ser particular de la clase oligárquica chilena de inicios del siglo XX, denominado "modo de ser aristocrático" por Barros y Vergara, quienes lo entienden como la suma de creencias, valores, categorías, conocimiento, que refieren a significados construidos por dicha clase desde su experiencia histórica y que identifica su comportamiento al concretarse en la conciencia de sus integrantes ${ }^{14}$. La vida cotidiana donde el buen tono predomina, se transforma e incorpora una serie de usos y hábitos externos a las prácticas que se daban tradicionalmente en el país, apareciendo "la hora del aperitivo, del five o 'clock tea, de la soirée"15. Asociado a

\footnotetext{
${ }^{10}$ Vicuńa, Manuel. La belle époque chilena. Alta sociedad y mujeres de élite. Santiago de Chile: Catalonia, (2010: 36).

${ }^{11}$ Ibíd., 33.

${ }^{12}$ Barros, Luis y Vergara, Ximena. El modo de ser aristocrático. El caso de la oligarquía chilena hacia 1900. Santiago: Ariadna ediciones. $2^{\circ}$ edición. (2007: 49).

${ }^{13}$ Ibíd., 112.

${ }^{14}$ Ibíd., 16.

${ }^{15}$ Ibíd., 112.
} 
estos usos y hábitos surge el consumo de productos específicos, los importados ${ }^{16}$. Lo señalado por Vial para 1890, respecto a lo que se internaba en el país desde el exterior, permite hacerse una idea de la variedad de estas mercancías, cuyo consumo permanece en las primeras décadas del siglo XX:

“...vinos, aguardientes y licores por casi ciento sesenta y siete mil libras esterlinas; dulces por una suma superior a ocho mil libras; juguetes por unas diez mil; guantes por más de siete mil; flores artificiales por más de cuatro mil; jabones aromáticos y perfumería por más de veintiún mil; pianos por una cantidad que excedía las veintiséis mil libra;, telas y terciopelo de seda, casi ochenta y siete mil libras; muebles, casi treinta y cinco mil; quesos más de cuatro mil, y "artículos para modistas" y "recortes y tiras bordadas", respectiva y exactamente, 55.985 y 16.779 libras esterlinas...."17

Tal consumo, asociado al "buen tono", al ser reflejo de una moda no priorizaría las características propias del objeto adquirido, o en otras palabras su valor de uso, sino más bien lo valorizado estaría dado en cuanto ser simbólicamente un signo de distinción. Como señalan Barros y Vergara, la moda instala una forma de consumir que prescinde del valor de uso y que omite la condición del objeto en cuanto tal, reduciendo su existencia al simple hecho de ser designado por las convecciones del buen tono, por lo que una moda "no sirve ya por la utilización que de ella pueda hacerse, sino porque su estilo y procedencia la convierte en símbolo de elegancia" ${ }^{18}$. Asimismo, este tipo de consumo requiere ser presenciado y compartido con los “iguales", pero también observado por los "diferentes", puesto que la ostentación de lo consumido - sea vivienda, vestimenta, vehículos, joyas, etc.- "buscaba proclamar y robustecer la superioridad social del grupo rector" ${ }^{19}$ y "tanto el ceremonial como el consumo mundanos son percibidos como signos de lo aristocrático y ello no es otra cosa que un aspecto más de la superioridad que se

\footnotetext{
${ }^{16}$ El excesivo consumo de mercancías foráneas es visto como escandaloso por algunos autores. Ver por ejemplo, Fernández, Enrique. Estado y sociedad en Chile, 1891-1931. El Estado excluyente, la lógica estatal oligárquica y la formación de la sociedad. Santiago: LOM Ediciones, (2003: 31); y Urbina, Rodolfo. Valparaiso. Auge y ocaso del Viejo "Pancho". 1830-1930. Valparaíso: Editorial Puntángeles, Universidad de Playa Ancha, Universidad Católica de Valparaíso, (1999: 443); por ejemplo. En el caso del primer autor, señala el "escándalo" de los montos alcanzados por artículos tales como joyas, sedería, perfumería y champaña para el periodo, mientras que Urbina alude a las palabras de Luis Ross para resaltar la ostentación porteña de inicios de siglo XX: "acaso fue un bien si con él [se refiere al terremoto de 1906] se lograra atajar el escándalo de la ostentación del lujo".

${ }_{17}$ Vial, Gonzalo. Historia de Chile 1891- 1973. La sociedad chilena en el cambio de siglo (1891-1920). Volumen I. Tomo II. $6^{\circ}$ edición. Santiago de Chile: Edición, Zig-Zag (2001: 643).

${ }^{18}$ Barros y Vergara, ob. cit., 49-50.

${ }^{19}$ Vial, ob. cit., 650.
} 
arroga la oligarquía" 20 .

El gran consumo no era una práctica exclusiva de la clase alta de Santiago, también ocurría en Valparaíso, la principal puerta de entrada de los productos extranjeros, hecho que favorecía su amplia oferta y permitía que la ciudad fuera considerada el "emporio del Pacífico sur". El aviso publicitario del Gran emporio Do, Re, Mi, Fa, aparecido en la Revista Sucesos, del 29 de julio de 1903, muestra la abundante oferta posible de encontrar en la ciudad, que en el caso específico de este comercio se refiere a productos alimenticios:

“¿Sabéis el gran suceso internacional? Pues acudid al Gran Emporio Do, Re, Mi, Fa y veréis que han llegado de Europa la mar de especialidades. Encontraréis: galatina de pavo, de pato, de ganso, de lengua, de pollo, de cordero, de ave, de ternera, de lengua de pavo, princesa y jamón de Paris. Unico depósito del afamado jamón Ausonia, queso de cabeza, queso de pavo, mortadela italiana y alemana, arrollado con o sin huevos, patos relleno, cabeza rellena, queso de lengua, queso Mieri, salchichón de Lorena, italiano, de Torino, milanés, salchichón crudo, cocido y de hígado de ganso, chorizos y longanizas de muchas clases y una infinidad de las más finas conservas escojidas especialmente para nuestra casa, todas de primer orden y 'primo cartello' ".

La publicidad de la época da cuenta de la amplia y variada oferta de artículos, que iban desde medicinas o productos relacionados con la salud o la belleza hasta animales exóticos, como los ofrecidos en el aviso publicitario de Duncan, Fox y Compañía, donde esta casa extranjera indicaba hacerse cargo de la importación de toda clase de animales, incluidos los exóticos ${ }^{21}$. La importancia del puerto de Valparaíso, en cuanto a la oferta comercial que allí se daba, se puede apreciar en el siguiente aviso publicitario aparecido en la revista Sucesos, del 4 de septiembre de 1930:

“Todos los días suntuosos transatlánticos y sólidos barcos de carga, llegan al Puerto de Valparaíso conduciendo lo más escogido de los mercados del Mundo a una de las Ciudades más ricas de Sud América. Ya sea un artículo de lujo o de primera necesidad, la demanda en Chile es siempre por lo mejor y no hay sal de mesa más fina que la pura, brillante y suelta

Sal de Mesa Cerebos".

\footnotetext{
${ }^{20}$ Barros Barros y Vergara, ob. cit., 66. Un ejemplo del simbolismo del consumo y su carácter diferenciador es el señalado por Vicuña para las mujeres de la élite santiaguina de inicios del siglo XX, a quienes los artículos de lujo les permitían, desde la posición de clase, resaltar simbólicamente la existencia de una diferencia de rango entre su sector social -detentores del poder en ese momento-y los desposeídos. ob. cit., 212.

${ }^{21}$ Ver Sucesos, Año IV, enero 1906.
} 
El comercio de la ciudad podía impresionar por su variedad. Eduardo Balmaceda, en "Valparaíso de mi niñez", plantea al respecto: “... era un comercio magnifico donde los santiaguinos iban a surtirse de importaciones inglesas, escasas en la capital, cuya mercadería venía en general de Francia”. Para él, Valparaíso era la única ciudad de Chile con carácter, entre otras razones, por tener una sociedad al estilo inglés, elegante y refinada, que despertaba curiosidad en los santiaguinos por las costumbres de las familias porteñas que les "aventajaban en algunos refinamientos" 22 . Como se mencionó con anterioridad, la publicidad, y lo ofertado a través de ella, constituye una fuente de información destacada al permitir, por ejemplo, informarse sobre fenómenos socioculturales ocurridos en el tiempo y espacio en que se realizan las prácticas publicitarias y de consumo. La publicidad comercial, que puede ser entendida como un "Proceso de comunicación de carácter impersonal y controlado que, a través de medios masivos, pretende dar a conocer un producto, servicio, idea o institución con objeto de informar o de influir en su compra o aceptación" ${ }^{23}$; es desde hace más de un siglo el medio para dar a conocer un producto y así generar su demanda. Como tal es utilizada desde el siglo XIX y en cuanto a la moderna publicidad comercial, aparece y se consolida en Estados Unidos, entre finales del siglo XIX y las primeras décadas del XX.

En el caso de Chile, tanto el incremento de la actividad productiva como el progresivo aumento de la circulación de bienes de consumo, favorecieron el nacimiento de una pequeña industria de la comunicación, siendo una inicial muestra de ello los anuncios clasificados de compra y venta de productos, abundantes en los periódicos chilenos posteriores a la consolidación de la Independencia ${ }^{24}$. En Valparaíso, la publicidad en medios impresos fue un recurso utilizado por comerciantes del puerto para dar a conocer las diversas mercancías y servicios ofrecidos, al igual que ocurría en otros países. Un ejemplo de lo señalado es la aparición del periódico El Aviso, en la segunda mitad del siglo XIX, con el objetivo de llevar "en el puerto más comerciante del Pacífico las inserciones de toda clase a un grado de publicidad proporcionalmente igual a la que existe en las principales ciudades de Europa" 25 .

\footnotetext{
22 Balmaceda, Eduardo. "El Valparaíso de mi niñez". En Memorial de Valparaíso. Alfonso Calderón y Marilis Sclotfeldt. Santiago: RIL editores, (2001: 401-402).

${ }^{23}$ Ortega, Enrique. citado por Pinedo, Antonio. "Propaganda y publicidad comercial: un principio diferenciador". En Questiones Publicitarias I/12 (2007): 107-128. Versión electrónica. Disponible en: <http://www.maecei.es/pdf/n12/ articulos/Propaganda_y_publicidad_comercial_un_principo_diferenciador.pdf $>$.

${ }^{24}$ Caselli, Pedro. Chile. Marca registrada. Historia general de las marcas comerciales y el imaginario del consumo en Chile. Santiago: Ocho libros editores, Universidad del Pacífico,( 2008: 56).

${ }^{25}$ Citado por Guerra, ob. cit., 7.
} 
A inicios del siglo $\mathrm{XX}$, diarios y revistas de circulación en ciudades como Valparaíso, Viña del Mar y Santiago contenían avisos publicitarios de mayor o menor complejidad en su presentación. En El Mercurio de Valparaíso, por ejemplo, a inicios del 1900, la gran mayoría de ellos eran de formato simple, del tipo del anuncio clasificado. A su vez, en revistas de la época, como Sucesos, la publicidad inicialmente ocupaba un número reducido de páginas para luego aumentar y aunque en sus primeros números -a comienzos de 1900- los avisos publicitarios eran de un formato simple en cuanto a imagen y texto, con el paso del tiempo empezaron a ser más elaborados ${ }^{26}$.

Las imágenes y el texto de los avisos publicitarios, no necesariamente promocionaban la mercancía o el servicio ofertado -generalmente se señalaba el tipo de producto y el nombre comercial-sino más bien, a partir de la incorporación de determinadas imágenes y de términos o adjetivos particulares, ofrecían simbólicamente un estilo de vida determinado -el de la aristocracia, que en algunos casos correspondía más a la europea que a la chilena- el cual tenía asociado un alcance contradictorio, ya que por una parte igualaba a quienes consumían los productos con este sector social y por otra, los diferenciaba de los sectores a los que consideraban "los otros"27.

En general, los hábitos de consumo contribuyeron al establecimiento de parámetros de imitación y diferenciación entre diversos actores de la sociedad chilena, "quienes vieron en la exhibición de bienes y productos la posibilidad de aproximar los desiguales ámbitos sociales"; donde el adquirir mercancías revestidas con signos distintivos no sólo ofrecía su disfrute, "sino también la posibilidad de apropiarse de marcas que distinguen socialmente al consumidor" 28 .

A la élite chilena, o la gente del buen tono, se le asociaba el monopolio del lujo, "del refinamiento, las maneras exquisitas, la elocuencia en el hablar, el consumo

\footnotetext{
${ }^{26}$ Aunque las razones del cambio en el tipo de publicidad aparecida en los medios impresos consultados no fue un aspecto estudiado, se considera que estarían relacionadas con el desarrollo mismo de la publicidad y sus técnicas, y además, con los requerimientos de las empresas que buscaban promocionar sus productos. En muchos casos, la matriz de impresión de los avisos publicitarios aparecidos en diarios y revistas locales, originalmente provenían del extranjero y eran modificados en los talleres de pre prensa para el medio local (Álvarez, ob.cit., 125).

${ }^{27}$ En la publicidad del periodo a su vez, se asociaba u homologaba iconográficamente a hombres y mujeres, o a cualidades culturalmente adscritas a cada sexo, con productos publicitados estimulando así la definición de los hábitos de consumo como rasgos de carácter masculino o femenino, al tiempo que impulsaba la construcción social de las identidades de género en relación a tales prácticas. Vicuña, ob. cit., 210.

28 Álvarez, ob.cit., 47.
} 
de los productos modernos, la apertura a lo extranjero"29. La publicidad de la época recurría a adjetivos asociados a estas características, los que formaban parte del "tipo humano socialmente valorado por la oligarquía", un hombre de mundo, elegante, "refinado, galante, de porte distinguido, elocuente, buen mozo", a la vez que también hace uso de virtudes que el sector oligárquico otorga al hombre y a la mujer de la élite: un caballero "que dejará constancia de su "chic" en el vestir, de su porte airoso, de sus maneras finas, de su hablar elocuente, de su actitud galante hacia la mujer" y una gran dama, que tendrá que ser hermosa y tener "ese no se qué, que sería la esencia del perfume aristocrático"30. Un ejemplo de lo señalado se puede observar en la publicidad de Polvos Mi Encanto, aparecido en Sucesos ${ }^{31}$. En éste, aunque se muestra la caja de polvos y se utiliza letra de mayor tamańo para el nombre, resalta la imagen de una pareja vestida elegantemente y el texto: "Para gustos refinados". El aviso contiene un texto y una imagen asociables a un estilo de vida refinado, que para ese momento era privilegio de la aristocracia, pero la revista no sólo llegaba a ese sector sino al que pudiera adquirirla, sectores medios por ejemplo, por lo que se puede pensar que el estilo refinado incorporado simbólicamente al producto, podía ser accesible por la mujer que los adquiriese ${ }^{32}$.

Los avisos publicitarios del periodo, en gran parte hacen uso de un lenguaje e imágenes que resaltan ciertas características o atributos asociados a la búsqueda por ser diferente en lo cotidiano, con un referente hacia lo europeo, principalmente francés. Dos anuncios publicitarios aparecidos en la revista Sucesos dan cuenta de ello. Uno corresponde al de Aguas de colonia Condal, que sólo contiene texto y donde se menciona a París, además de indicarse que son las preferidas y adoptadas por la gente $\mathrm{chic}^{33}$. El hecho de señalar la palabra Paris remite necesariamente a Francia, principal referente de distinción para la élite chilena, mientras que el término "gente chic" hace alusión al sector al que se le asocia esta condición. A su vez, en la publicidad de la crema italiana Venus Bertelli ${ }^{34}$, que también incluye sólo texto, se señala que es "la crema para la cara que más se usa en Europa", así como que "la aristocracia y las celebridades artísticas mundiales la prefieren". Estos

\footnotetext{
${ }^{29}$ Barros y Vergara, ob. cit., 56.

${ }^{30}$ Ibíd., 31-32.

${ }^{31}$ Año XIX, no. 16, 10 de abril 1931.

32 Álvarez seńala que los modos de comportamiento de la élite chilena ejercieron una importante influencia en los estilos de vida de las capas medias, para quienes la ostentación era vista como una manera de invalidar formas previas de distinción social. Ob. cit., 45.

${ }^{33}$ Revista Sucesos, Año VIII, no. 919, 6 de mayo 1920.

${ }^{34}$ Sucesos, Año V, no. 262, 12 de septiembre 1907.
} 
dos aspectos pueden ser considerados como "facilitadores de la diferencia" en quien la consuma, aunque ello signifique "igualarse" a consumidores europeos y a la aristocracia y celebridades artísticas, lo cual desde el punto de vista simbólico llegaría a ser un referente trascendente para la consumidora local del producto.

Las diferencias entre clases sociales no sólo se dan a partir del consumo de determinadas mercancías o servicios, también lo es a partir del acceso o "consumo" de espacios físicos y a lo que en estos se consume u ostenta. Este aspecto es señalado en el artículo denominado "En la playa popular", publicado en la revista Sucesos del 4 marzo de 1920, donde se hace una narración sobre las playas de Recreo, Miramar y Caleta, lugares de distracción de habitantes de Valparaíso y Viña del Mar.

"En Recreo y Miramar hay palmitos azucarados, en Caleta también se encuentran, no tan dulces pero amargos tampoco... En aquéllas están las damas del manguito y la mantilla; en la Caleta no escasean las que tienen la sartén por el mango... y el control de los manteles. A Recreo y Miramar, van las damas que dejan las guaguas en casa; a la Caleta, las que cuidan a las guaguas. En aquellos balnearios hay mucho olor a habano y a esencia importada; en la Caleta a trigos regulares y a destilería nacional. Los bañistas de Miramar y Recreo después del baño se sirven helados con pasteles; en la Caleta hay más baratura: se sirven tonguitos con tortillas. Por allá se sirve chartreuse, benedictine y jérez; por acá cognac bandera, guindado o media Pilsen, según los sueldos...”.

\section{PUBLICIDAD Y ELEMENTOS DIFERENCIADORES A INICIOS DEL SIGLO XX}

Como se ha señalado con anterioridad, la publicidad tiene como principal función el influir en la compra o aceptación de un determinado bien o servicio. Es por ello que recurrirá a imágenes y texto, para llamar la atención de los potenciales consumidores. En la publicidad del periodo revisado, algunos de los términos utilizados en el texto de los avisos estaban directamente relacionados con características que la oligarquía o aristocracia consideraban destacables para resaltarlos como tales. Por ejemplo, se aludía a la elegancia, a la suprema elegancia o a la refinada elegancia. Así también se hacía uso de los términos chic, buen tono, buen gusto, gusto refinado, gusto exclusivo, fineza, refinado, finura, distinción, signo de distinción, distinguido, superior. La palabra aristocracia era utilizada 
de manera frecuente como también lo era "alta sociedad" o sociedad. En lo que respecta a imágenes, aunque en varios avisos publicitarios se recurría a la imagen del producto publicitado, ésta era acompañada muchas veces por las figuras de un hombre o una mujer, una pareja, o grupos de personas vestidos de "manera elegante" (generalmente esmoquin o frac en el caso de varones, o vestidos de fiesta y pieles en las mujeres). Así también se utilizaban las figuras de doncella, chofer, mayordomo, mozo o "sirvienta"; los que generalmente aparecían sirviendo o atendiendo a los primeros.

La publicidad que hacía uso de imágenes de sectores sociales diferentes a la aristocracia u oligarquía no es abundante en los medios de comunicación revisados y en especial para las dos primeras décadas. En general, y además de quienes desempeñaban actividades de servicio, los avisos publicitarios recurrían a las figuras de obreros o trabajadores y "rotos" 35 , y estaba relacionado con la oferta de algún producto dirigido especialmente a esos sectores o que su consumo buscaba de manera directa, establecer algún tipo de "acercamiento" entre distintos sectores sociales.

Algunos de los avisos publicitarios que hacen uso, tanto en el texto como en las imágenes, de elementos que resaltaran el consumo del producto ofertado como exclusivo de la élite chilena, corresponden a los que promocionaban champaña y licores como whisky y cońac. A estos productos, y a quienes los consumen, se les asociaban términos como buen gusto, distinción, aristocracia o aristocrático, o elegante distinción; y en ciertos casos de champaña, se recurre también a palabras como gente distinguida, buen tono y corte europea. Y no sólo en la oferta de licores o champaña se aludía a características como las señaladas, también ocurría con otros productos bebibles como el agua mineral; por ejemplo el agua mineral El Milagro, donde el aviso publicado el 22 de diciembre de 1910 en la revista Sucesos, señala:

"Siempre tratando del agua mineral "El Milagro". Esta es agua que se recomienda: a la Créme, A la Élite, A la high-life de la sociedad, y a toda persona de gusto refinado".

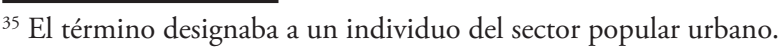


Asimismo, los perfumes y artículos de tocador como cremas y polvos hacen uso en su publicidad de términos o adjetivos calificativos - para el producto o para quienes los consumen- como chic, distinguido, elegante o refinada elegancia, buen gusto o gusto refinado, gracia, distinción o nota de distinción, fino o fineza, delicadeza. A los artículos antes señalados se agregan cigarrillos, té, jabones de tocador, telas, vestuario femenino y masculino, calzado, vinos, algunos productos alimenticios como aceite de oliva, y automóviles, siendo estos últimos vistos como símbolos de estatus aristocrático, al igual que lo ocurrido con el carruaje para siglo $\mathrm{XIX}$ e inicios del $\mathrm{XX}^{36}$.

Si bien el té es resaltado en algunos avisos como un producto consumido por "la alta sociedad", "las damas cultas", "la gente distinguida", o como una necesidad del buen tono: "El five'o clock tea. Más que la necesidad de beber Té, lo produce la necesidad de la sociabilidad y del buen tono. Cuide usted que en sus Tés sea el TE SUPERIOR la primera demostración del buen gusto y delicadeza. Wier, Scott \& Company" ${ }^{37}$.

En otros avisos publicitarios se le concede un carácter más igualitario, como el del té Ratampuro publicado en El Mercurio de Valparaíso, del 18 de marzo 1910, donde se señala: "El té de los pobres: pues es el más económico. El té de los ricos: es el más delicioso. El té de los conocedores. El favorito de todos. El mejor”.

Cabe destacar que el uso de ciertos términos o adjetivos en la publicidad de algunos productos destinados a la élite chilena, estaba muy relacionado con la procedencia de las mercancías; se valoraba altamente que vinieran del extranjero, especialmente de Europa. ${ }^{38}$ La relación con los países del viejo continente no sólo se circunscribía a la procedencia de las mercancías, sino también aludía al hecho de que el nombre de la mercancía, de la línea o de la tienda que ofertaba ciertos

\footnotetext{
36 Álvarez, ob. cit., 647.

${ }^{37}$ Revista Sucesos, Año XVIII, no. 924, 10 de junio 1920.

${ }^{38}$ No sólo era posible acceder a mercancías extranjeras a partir de la compra en el país, también lo era encargándolas directamente a Paris o Londres -en el caso de los sectores más adinerados, (Álvarez, ob. cit., 648) - o en la visita que se hiciese a la tienda o por medio de compra por catálogos como ocurría con almacenes de Estados Unidos. En la revista Sucesos del 3 de enero de 1918, aparece un aviso de una página de la tienda B. Alman \& Co., donde se publicita la venta por catálogo de esta tienda ubicada en Nueva York o la compra en la tienda, la cual es señalada en el aviso como "La tienda de la aristocracia. Especializada en atavíos elegantes y a la moda para señoras, señoritas, nińas y niños", donde "El mismo gusto artístico y discernimiento refinado de la selección de las mercancías prevalece en todos los departamentos de casa, mereciendo especial mención las secciones reservadas para sedas, terciopelos y otros tejidos, encajes, blondas y embutidos, adornos, pasamanería y novedades, perfumería y artículos de tocador...".
} 
productos nacionales o extranjeros incorporase algún término relacionado con Francia, Inglaterra o algún país europeo. Algunos ejemplos de lo señalado son los siguientes:

"Línea Paris. Ultima creación de Coty. Polvos. Esencias. Lociones. Brillantina todo perfumado a un mismo extracto: Paris" ${ }^{\prime \prime}$.

"Paris. Todo el mundo conoce el inmenso poder de seducción de que disfruta la elegante y hermosa mujer de Paris, la luminosa y esplendente ciudad. Pero no todo el mundo sabe que, en gran parte, ese seductor poder de la "parisienne" le proviene de la tersura, suavidad y limpidez de su cutis... Usando Cera Mercolizada, podréis, como las bellas parisinas, lucir un aterciopelado cutis, causa y origen de la poderosa fascinación" ${ }^{\prime 40}$.

"Al pedir Ud. un coñac exija del mozo LA MARCA "FRAPIN". La casa Frapin es la más importante productora de Cońacs de Francia, como lo puede comprobar el gran Premio del Presidente de la República, que le ha sido otorgado a este título"¹.

"Camisas inglesas y austriacas. Blancas y de color un grandioso surtido a precios sin competencia. Ofrece Prince of Wales”42.

El uso de idiomas diferentes al español en la publicidad del periodo revisado, constituye un factor diferenciador incorporado en la oferta de algunos productos, considerando que el mensaje se dirigía a sectores particulares del público consumidor, aquellos con conocimiento de idiomas hablados en Europa, los que podían ser miembros de la aristocracia local o habitantes extranjeros de la ciudad. En El Mercurio de Valparaíso del 6 de abril de 1910, se hace uso del inglés para publicitar un brandy: "Brandy. The Consumer's only Question: It's MARTELL'S? If in doubt, ask for the BLUE and SILVER LABEL". En la revista Sucesos, del 14 de abril de 1910, se publicita un vermouth en francés: "Cinzano. Le contenu de la bouteille est le meilleur avocat du Cinzano. En vente partout". Y no sólo eran licores o champañas los que utilizaban otros idiomas en la publicidad, principalmente francés, para promocionar el producto, también lo hacían artículos de tocador como cremas y perfumes. Un ejemplo es el aviso de Bourjois, en él se señala: "GRACE, ÉLÉGANCE, JEUNESSE. SOIR DE PARIS. UN NOUVEAU PARFAM DE BOURJOIS. PARFUMEUR- PARIS. Créateur

\footnotetext{
${ }^{39}$ Revista Zig -Zag, Año XXXV, no. 1790, 13 de julio 1939.

${ }^{40}$ Revista Sucesos, Año XXVI, no. 20, 5 de enero 1928.

${ }^{41}$ Revista Sucesos, Año IX, no. 435, 5 de enero 1911.

${ }^{42}$ El Mercurio de Valparaíso, viernes 9 de abril 1910.
} 
de MON PARFUM"43.

Se puede apreciar entonces, que la publicidad del periodo estudiado recurre a factores como adjetivos o términos específicos asociados a la élite o alta sociedad chilena, y a la vez porteña, en su texto, así como también a idiomas como inglés o francés para dirigirse a este sector, al cual oferta mercancías vinculadas a un consumo de tipo conspicuo. Los términos elegante, distinción, chic y aristocracia eran usados de manera frecuente en los avisos publicitarios aparecidos en diarios y revistas; algunos los incorporaban muy directamente en el texto, para acentuar al sector de consumidores al que estaba dirigido el producto. Los avisos del champaña Saint Marceaux dan cuenta de esta situación:

"Champagne "Saint Marceaux". Cuanto de más selecto hay en las sociedades, lo consumen. La gente Chic, distinguida y elegante, lo prefiere" ${ }^{44}$.

"Champagne ST. MARCEAUX proclamado por la aristocracia de la sangre, de las armas, de las letras y del dinero como superior a todas las conocidas" $\$$.

En la publicidad del talco Williams ${ }^{46}$ se recurre también al término aristocrático, el cual es asignado al producto, así como a elegante. Además, se destaca la diferencia existente entre un talco aristocrático y uno ordinario, condición que podría extenderse, indirectamente, hacia quien consume uno $\mathrm{u}$ otro talco. Este aviso utiliza también una imagen de "mujer elegante", para asociar el producto con las potenciales consumidoras. Otro ejemplo sobre el uso de términos asociados con la élite en avisos publicitarios es el aparecido en la revista $Z i g-Z a g^{47}$. En este se señala: Fanal de Lohse. Un perfume sutil y arrobador para la gente "chic". El perfume está dirigido directamente a la gente chic, la cual es representada en el aviso mediante la imagen de una mujer vestida de manera "elegante", que está usando joyas y que tiene a su disposición tres productos de la marca publicitada. A su vez, la publicidad del champagne Montebello ${ }^{48}$, muestra dos elementos mencionados con anterioridad en este trabajo, el uso de términos o adjetivos específicos en el texto y de imágenes que dan cuenta directa y simbólicamente

\footnotetext{
43 Revista Sucesos, Año XIX, no. 1468, 13 de noviembre 1930.

${ }^{44}$ Revista Sucesos, Año XII, no. 583, 6 de noviembre 1913.

${ }^{45}$ Revista Sucesos, Año XII, no. 587, 4 de diciembre 1913.

${ }^{46}$ Revista Zig-Zag, Año XXXV, no. 1766, 5 de enero 1939.

${ }^{47}$ Ańo XX, no. 1043, 14 de febrero 1925.

${ }^{48}$ Revista Sucesos, Año IX, no. 475, 12 de octubre 1911.
} 
de calificaciones o situaciones relacionadas con un determinado sector social, la aristocracia, y con su modo de ser. Este sector es el que accede a productos como champagne Montebello y lo puede hacer en un ambiente y en las condiciones mostradas en el aviso: elegantes y en un espacio confortable; es "gente distinguida y de buen gusto" ${ }^{49}$.

Como se señaló con anterioridad, las imágenes utilizadas en los avisos publicitarios revisados no necesariamente refieren directamente al producto ofertado, muchas veces muestran más bien al público al que se buscaba interesar en la mercancía o servicio publicitado y en los aspectos simbólicos asociados a su consumo y a la vez, a la distinción social involucrada. Esto se puede apreciar en la siguiente publicidad aparecida en la Revista Sucesos ${ }^{50}$.

Aunque en el aviso se alude textualmente al jabón de Ross, la imagen no presenta el producto sino a quienes pueden usarlo, mujeres que lucirán en sociedad un cutis blanco. El tipo de vestimenta de las mujeres así como el mobiliario del ambiente donde se encuentran dan cuenta de su pertenencia a un sector social privilegiado, por lo que el consumo del jabón de Ross se asocia en la publicidad a mujeres de clase alta.

La aparición del automóvil en el país y a la vez en Valparaíso, hizo que este producto fuese relacionado directamente con el lujo, elegancia, distinción, buen gusto y aristocracia. Gran parte de la publicidad de automóviles recurrió en su texto a los términos señalados, incluso, en algunos casos se usó el hecho de que la aristocracia de países determinados o la nobleza europea utilizara el modelo publicitado, para resaltar el carácter simbólico que podía implicar el acceso a este producto. Por ejemplo, en Sucesos de junio de 1920 aparece la publicidad de Cadillac, donde se habla de "El Príncipe de Asturias, hijo mayor del Rey don Alfonso XIII, de 13 años, manejando un automóvil Cadillac" y se presenta una fotografía que

\footnotetext{
${ }^{49}$ Las personas que aparecen en el aviso publicitario no estarían refiriendo necesariamente a habitantes de de Valparaíso o Chile en general, pero sí del sector social al que se alude en la publicidad, que bien pudiera ser europeo. Muchos de los individuos presentados en los avisos publicitarios no poseen los rasgos físicos de la población chilena en general. Además, se debe considerar lo señalado por Carlos Bonfil, citado en el trabajo de Álvarez, "la falta de dibujantes comerciales se hacía notar tan gravemente en las ilustraciones de los anuncios, que la mayoría de ellos tuvieron que plagiar los avisos que aparecían en revistas y diarios extranjeros" (ob. cit., 133).

${ }^{50}$ Año XXIII, no. 10207, 7 de noviembre 1925.
} 
testimonia lo señalado en el texto ${ }^{51}$. A su vez, en la misma revista de marzo de 1920, el texto del aviso publicitario de Packard Twin-Six, señala: Por su confort insuperable y sus formas de suprema elegancia es el automóvil de la aristocracia americana. Al lujo y refinamiento de los automóviles europeos, reúne la eficiencia y calidad de los coches americanos... 52

Así como existía publicidad dirigida específicamente al sector social aristocrático, donde el producto es publicitado mediante textos o imágenes que dan cuenta de este sector, también -aunque no de manera abundante- los medios impresos consultados insertan publicidad de productos, que en cuanto mercancías genéricas se dirigen tanto al sector seńalado como en específico hacia los sectores medios y populares. Es el caso de la publicidad de cigarrillos, donde se da tanto una oferta diferenciadora como una que iguala o que se dirige en específico a sectores populares. Algunos ejemplos son los avisos aparecidos en el diario La Unión, donde en uno de ellos se señala: "Los elegantes solo piden Libaneses. Tabaco egipcio" "53; mientras que en otros se utilizan los términos chic: "La gente chic fuma cigarrillos Babilonia" ${ }^{54}$ y aristocrático: "El cigarrillo aristocrático para paladares exigentes "The Dandy" "V5; "Veraneantes. Es signo de distinción fumar los aristocráticos cigarrillos Wetsminster. Con Boquilla de Oro para señoritas y caballeros recientemente puestos en venta en las principales Cigarrerías" 56 .

Respecto a la publicidad que recurre a una oferta que iguala o que se dirige al sector popular, están los avisos de los cigarrillos Opinión, en el que se indica: ¡Camaradas, adoptemos con orgullo y decisión, los triunfantes, los supremos

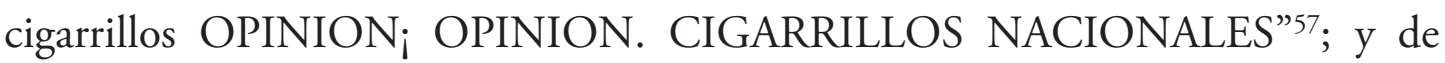
Sublimes:

\footnotetext{
${ }^{51}$ Año XVIII, no. 923, 24 de junio.

${ }^{52}$ Año XVIII, no. 913, 18 de marzo.

${ }^{53}$ Diario La Unión, jueves 9 de marzo 1922, p. 6.

${ }^{54}$ Diario La Unión, jueves 12 de marzo 1922, p.7.

${ }^{55}$ Diario La Unión, miércoles 17 de enero 1934, p. 5.

${ }^{56}$ Diario El Mercurio de Valparaíso, domingo 24 de enero, 1926, p. 1.

${ }^{57}$ Diario La Unión, miércoles 10 de enero 1934, p. 5.
} 
"Ahora no solo los capitalistas pueden fumar bueno... También los empleados tienen un cigarrillo, que está a su alcance y que es lo más SUBLIME que se puede fumar. "SUBLIMES". Habanos corcho. Sublimes por su Calidad Exquisita. Sublimes por su Presentación Elegante. Sublimes por Precio Económico. Sublimes por su Valiosa Propaganda"s8.

Las mercancías ofertadas se encuentran en directa relación con el consumidor al que se pretende llegar y de acuerdo a ello, la publicidad hará uso de un determinado lenguaje o de imágenes específicas para referirse al sector social objetivo. Es así por ejemplo, que licores y champaña, perfumes, automóviles, pieles, ciertas telas o prendas de vestir y algunos productos de tocador o belleza son ofertados para la élite o aristocracia local, mientras que otros como cigarrillos, cerveza, y en algunos casos vino y té, son publicitados para consumidores de sectores medios y populares, o para diferentes sectores sociales.

La publicidad de la Compañía Cervecerías Unidas es un ejemplo de lo señalado; en ella se muestra la imagen de dos hombres, uno representado a través de la vestimenta como obrero y otro como patrón, que se acompańa con el texto: "Para obrero y patrón no hay bebida más sana, nutritiva y fortificante y menos dañina que la CERVEZA. Tómela en las comidas y a toda hora..." 59 . Asimismo, el aviso publicitario de Viña Casa Blanca utiliza la imagen de un personaje popular, Verdejo, que estaría siendo usado simbólicamente para representar a un individuo del pueblo, señalándose: "Hasta Verdejo prefiere los vinos de la VIÑA CASA BLANCA"60.

Otros avisos que incorporan al sector popular son los del té Ratampuro, uno de ellos ya aludido con anterioridad, donde se destaca el producto como el té de los pobres y de los ricos, ${ }^{61}$ y otro que señala: "En verdad, toda la mercancía está cara, menos el exquisito Té Ratampuro", y se muestra la imagen de un grupo de compradores que lo demandan en un almacén de barrio ${ }^{62}$. A su vez, es posible apreciar en otros avisos publicitarios cómo el producto publicitado se dirige a potenciales compradores de un sector social específico o de sectores diversos. En

\footnotetext{
${ }^{58}$ Diario La Unión, miércoles 12 de enero 1934, p. 7.

${ }^{59}$ Diario La Unión, Lunes 10 de diciembre 1928, p. 20.

${ }^{60}$ Verdejo es el personaje de la revista de sátira política Topaze, que circuló en Chile entre los años 1931 y 1970, el cual se transformó en una representación gráfica del pueblo.

${ }^{61}$ El Mercurio de Valparaíso, 18 de marzo 1910, p. 7.

${ }^{62}$ Revista Sucesos, Año XVII, no. 905, 29 de enero 1920.
} 
la publicidad del Jabón Obrero, el texto -que da cuenta de las propiedades del producto en cuanto tal- es acompañado por la imagen de un trabajador y una fábrica:

"Jabón Obrero, para quitar toda clase de manchas y suciedades adheridas a la piel. Nada más agradable y eficaz, para quitarse rápidamente las suciedades de grasa, de aceite, de pinturas o tintes, substancias pegajosas que manche y se adhiere a la piel, que unos lavados con Jabón Obrero... Se hace uso de la imagen de un trabajador y una fábrica tras él”63.

Económica y Cooperativa El Progreso, recurren principalmente al texto para promocionar no tanto al producto, sino más bien para resaltar las cualidades de las tiendas: estar abierto a un público amplio de diferentes sectores sociales, ofrecer un surtido de artículos a precios "económicos" o "fuera de competencia". En este caso, es el precio del producto y también la venta a plazos, los elementos que permiten "igualar" el consumo entre sectores diversos.

"Vox Populi... El pueblo, la burguesía y la aristocracia, que es como si dijéramos la masa de la población de Valparaíso, se han unido, se han puesto de acuerdo, están conformes en declarar todos a la una, libremente, sin instigaciones de nadie, que LA INFANTIL ha venido a prestar un servicio grandísimo a las familias ¿Qué por qué? Sencillamente porque hacía falta en Valparaíso una casa ESPECIAL en artículos para NIÑOS, en la cual se encontrará un surtido espléndido de todo..." ${ }^{64}$

"Gran Zapatería La Victoria... Que en tan poco tiempo se ha hecho célebre por el espléndido surtido y sus precios tan sumamente baratos y que ha satisfecho una verdadera necesidad para el populoso barrio del Almendral que necesitaba desde hace tiempo un negocio como el que con gusto publicamos la fotografía. Llama la atención de todos los transeúntes de la calle Victoria la confraternidad que reina entre los compradores de esta casa. Allá se ve todos los días compradores desde lo más aristocrático hasta el más humilde de la sociedad porteña que se satisface de comprar calzado cosido a mano, e importado legítimo, a precios tan fuera de competencia..." 65

"Sociedad Cooperativa El Progreso. Surtido de Abarrotes, Géneros blancos, Casimires y Calzado. Precios sumamente económicos. Se atiende al público de 6 a10 PM.

Todos los obreros deben formar Sociedades Cooperativas para aliviar su situación económica, en ellas se vende más barato y el peso es siempre exacto" ${ }^{\text {"66. }}$.

\footnotetext{
${ }^{63}$ Revista Zig-Zag, Ańo XVI, no. 9 de octubre 1920.

${ }^{64}$ Revista Sucesos, Año I, no. 15, 1 de octubre de 1902.

${ }^{65}$ Revista Sucesos, Ańo XI, no. 539, 2 de enero 1913.

${ }^{66}$ Revista Sucesos, Año VIII, no. 395, 31 de marzo 1910.
} 
"LA "ECONOMICA". La pobreza no hace la miseria. El más modesto empleado. El trabajador más humilde puedn vivir con la higiene, el confort y la decencia, que la salud, la vida y la sociedad exigen, sin alterar sus presupuestos ni arriesgarse a violencia financiera. La cuestión está en saber comprar. "La Económica" ofrece en venta A PLAZOS y al precio reducido de remate..." 67

Es necesario destacar, que el hecho de que apareciera publicidad que promueve productos o servicios dirigidos a consumidores diversos socialmente, no necesariamente significa que el consumo o la oferta en el periodo revisado se haya "democratizado". Ni la publicidad de determinados productos -como licores, artículos de tocador o algunos alimentos importados- está dirigida a cualquier potencial consumidor ni el consumo de algunas mercancías es indiferenciado, como es el caso del Jabón Obrero o de los cigarrillos Opinión. Aunque ciertos sectores sociales, como el medio y el trabajador, buscaron "diferenciarse de las capas más bajas, de las que a menudo provenían, esforzándose por imitar a la clase alta, y -para horror de la vieja aristocracia-, en parte lo pudieron lograr"68; esto se vio favorecido porque las industrias locales empezaron ofertar sus productos, muchas veces imitaciones de los provenientes del extranjeros y no de similar calidad.

La amplia oferta comercial, en especial de productos importados, que se dio en la ciudad de Valparaíso, contribuyó a que sectores sociales privilegiados de la sociedad porteña tuvieran a su alcance, numerosos y diversos artículos para su consumo. Se bebía champaña Rei, "la marca del más grande consumo en el universo. Proveedores titulados de todas las cortes europeas, del cuerpo diplomático y de la aristocracia mundial" ${ }^{69}$, o el whisky Watson $\mathrm{N}^{\circ} 10$, "el whisky que consume la aristocracia inglesa..."70; se consumía té Dulcinea, que "es siempre el preferido en las recepciones de buen tono"; o se vestía en la Maison Chic, "la Casa preferida por la elegante sociedad porteña” ${ }^{71}$.

La revisión de publicidad en medios impresos con circulación en Valparaíso durante los años 1900 a 1940, permitió conocer que la promoción de un consumo diferenciador en avisos publicitarios de diarios y revistas se dio de manera más

\footnotetext{
${ }^{67}$ Revista Sucesos, Año IX, no. 466, 10 de agosto 1911.

${ }^{68}$ Álvarez, ob.cit., 52.

${ }^{69}$ El Mercurio de Valparaiso, lunes 25 de abril de 1910, p. 3.

${ }^{70}$ Revista Sucesos, Año XI, 22 de mayo de 1913.

${ }^{71}$ El Mercurio de Valparaiso, lunes 4 de enero 1926, p. 3.
} 
fuerte en las dos primeras décadas del siglo XX, aunque permaneció hasta fines del periodo revisado; años en que empieza a ser más recurrente en la publicidad la referencia a la procedencia nacional de mercancías promocionadas ${ }^{72}$. Dos avisos aparecidos en El Mercurio de Valparaíso grafican lo seńalado: "Hucke. Productos que honran la industria nacional"; "Sea patriota. Fume cigarrillos hechos en Chile por operarios chilenos y ayudará al progreso de la industria nacional"73. Además de lo referente al producto particular, en ambos anuncios se incorpora una imagen con el texto: "Compre productos Chilenos".

\section{REFLEXIONES FINALES}

La promoción de un consumo que permitiera expresar estatus a quien la realizara y la oferta de productos que lo favorecían, en la publicidad de las primeras décadas del siglo XX, no estaba ajena al marco sociocultural existente en el periodo, donde la élite chilena y su modo de ser, el modo de ser aristocrático como señalan Barros y Vergara, cuyo referente era la aristocracia europea, imponían su visión de mundo y su estilo de vida, compartido entre iguales y lejano a los "diferentes", "los otros". Esta búsqueda del consumo de mercancías revestidas simbólicamente de signos distintivos o diferenciadores fue incorporada en la publicidad aparecida en medios impresos de la época.

Actualmente, el estilo publicitario no está lejano del existente en las tres primeras décadas del siglo XX. Los avisos publicitarios no sólo buscan promover el consumo del producto publicitado, venden un estilo de vida y la marca más que la mercancía es la que se reviste simbólicamente con signos y significados diferenciadores. Quizás, tal consumo no esté sólo limitado a los sectores privilegiados como ocurría en los ańos estudiados y más bien alcance un carácter democrático, todavía más si se disponen de mercancías "alternativas" - una forma diferente de nombrar a las falsificaciones- de marcas que se consideran distintivas y que permiten hacer sentir a quienes las consumen, que ya no son "los otros", en una sociedad donde cada vez más el tener y no el ser es lo que otorga sentido.

\footnotetext{
${ }^{72} \mathrm{Si}$ bien en décadas anteriores se publicitaban mercancías de origen nacional, como vinos, licores o cigarrillos, estas muchas veces se hizo utilizando adjetivos asignados a los artículos importados, o se les nombraba recurriendo a palabras en inglés o francés.

${ }^{73}$ El Mercurio de Valparaíso, viernes 8 de enero 1932, pp. 8 y 9.
} 


\section{REFERENCIAS}

Fuentes primarias

Revista Sucesos: Valparaíso, años de 1902, 1907, 1910, 1911, 1913, 1920, 1925, 1928, 1930, 1931.

Revista Zig-Zig: Valparaíso, años de 1920, 1925, 1939.

Diario El Mercurio de Valparaíso: Valparaíso, años de 1910, 1926, 1932.

Diario La Unión: Valparaíso, años de 1922, 1928, 1938.

Fuentes secundarias

Balmaceda, Eduardo. "El Valparaíso de mi niñez”. En Memorial de Valparaíso. Santiago de Chile: Alfonso Calderón y Marilis Sclotfeldt. RIL editores, 2001.

Barros, Luis y Vergara, Ximena. El modo de ser aristocrático. El caso de la oligarquía chilena hacia 1900. Santiago de Chile: Ariadna ediciones, $2^{\circ}$ edición, 2007.

Caselli, Pedro. Chile. Marca registrada. Historia general de las marcas comerciales y el imaginario del consumo en Chile. Santiago de Chile: Ocho libros editores, Universidad del Pacífico, 2008.

Estrada, Baldomero. "Poblamiento e inmigración en una ciudad puerto. Valparaíso 1820-1920", Serie Monografías Históricas N¹2, Valparaíso, sociedad y economía en el siglo XIX. Baldomero Estrada et al. Valparaíso: Instituto de Historia, Universidad Católica, 2000.

Fernández, Enrique. Estado y sociedad en Chile, 1891-1931. El Estado excluyente, la lógica estatal oligárquica y la formación de la sociedad. Santiago de Chile: Ediciones LOM, 2003. 
Guerra, Alejandra. "La imagen de sí: ser y parecer. El surgimiento de nuevos hábitos de consumo. Valparaíso 1840-1860”. Tesis de Magíster. Valparaíso: Universidad Católica de Valparaíso, 2002.

Palma, Daniel. "De apetitos y de cañas. El consumo de alimentos y bebidas en Santiago a fines del siglo XIX", Revista Historia, Instituto de Historia Pontificia Universidad Católica de Chile, 37/ II, julio-diciembre 2004. Versión on line. Disponible en: < http://www.scielo.cl/scielo. php?pid=S0717-71942004000200005\&script=sci_arttext $>$. [Consultado: el 5 de abril de 2012].

Pinedo, Antonio. "Propaganda y publicidad comercial: un principio diferenciador", Questiones Publicitarias I/12 (2007): 107-128. Versión electrónica. Disponible en: <http://www.maecei.es/pdf/n12/articulos/Propaganda_y_ publicidad_comercial_un_principo_diferenciador.pdf $>$.

Silva, Víctor Domingo. Monografía Histórica de Valparaíso 1536-1910. Viña del Mar: Ediciones Altazor, 2004.

Urbina, Rodolfo. Valparaíso. Auge y ocaso del Viejo "Pancho". 1830-1930. Valparaíso: Editorial Puntángeles, Universidad de Playa Ancha, Universidad Católica de Valparaíso, 1999.

Vial, Gonzalo. Historia de Chile 1891-1973. La sociedad chilena en el cambio de siglo (1891-1920).Volumen I. Tomo II. $6^{\circ}$ edición. Santiago de Chile: Edición, Zig-Zag, 2001.

Vicuña, Manuel. La belle époque chilena. Alta sociedad y mujeres de élite. Santiago de Chile: Catalonia, 2010.

Yábar, Juan. Valparaíso 1536-1910. Recopilación Histórica, Comercial y Social. Valparaíso: Imprenta Minerva, 1910. 